\title{
Seafarers' awareness-based domain modelling in restricted areas
}

\author{
Hee-Jin Lee, ${ }^{1 *}$ Yoshitaka Furukawa, $^{2}$ and Deuk-Jin Park $^{3}$ \\ ${ }^{1}$ Department of Maritime Engineering, Graduate School of Engineering, Kyushu University, Fukuoka, Japan. \\ ${ }^{2}$ Department of Marine Systems Engineering, Faculty of Engineering, Kyushu University, Fukuoka, Japan. \\ ${ }^{3}$ Division of Marine Production System Management, Pukyong National University, Busan, Korea Republic. \\ *Corresponding author. E-mail: lee.heejin.600@s.kyushu-u.ac.jp
}

Received: 4 November 2020; Accepted: 2 April 2021; First published online: 4 May 2021

Keywords: ship domain, ship collision, safety

\begin{abstract}
Applying the existing domain model in ship domain research in a restricted area can be difficult owing to multiple factors that must be considered. This study presents a new domain model that can be applied in such environments. According to Endsley's theory of situation awareness, people have their own criteria in decision making based on factors such as individual and environmental factors. To investigate these factors, 125 seafarers were interviewed and threshold values based on their awareness were examined. The factors were evaluated as the closest points of approach. Domain modelling was performed based on these seafarer awareness values; then, the existing and awareness domains were compared, revealing that the awareness-based domain of seafarers is more affected by ship manoeuvrability than by ship size and speed, unlike the findings of existing domain research. Therefore, this study presents a new domain model that is both realistic and practical in a confined area, including various factors considered by seafarers based on the awareness values formed.
\end{abstract}

\section{Introduction}

Ship domain research is a crucial factor in marine safety; it includes the safe operation of ships, traffic diagnostic evaluation and collision avoidance (Rawson et al., 2014; Szlapczynski et al., 2018). The concept of ship domain was first presented by Fujii and Tanaka (1971). The ship domain quantifies the safe distance of passage between a seafarer's own ship and other ships in proximity; it also identifies a safety area around the ship. Most domain studies have been conducted to determine domains of ships sailing in open water. Therefore, applying the domain models for practical use in restricted areas is difficult. Since the concept of ship domain was proposed, ship domain research has been performed using various methods (Liu et al., 2016; Szlapczynski and Szlapczynska, 2017; Im and Luong, 2019). There are several types of ship domain models; three types in particular are discussed below (Im and Luong, 2019).

The first type of ship domain model is a statistics-based model of ships' passages. This first model was designed by Fujii as an elliptical domain by acquiring data through radar observation in open water off Japan (Fujii and Tanaka, 1971). Goodwin's model (Goodwin, 1975), which was based on radar observation data in the same manner, was designed in a circular form by dividing the ship domain into three areas. Davis et al. (1980) improved Goodwin's model by placing the ship's position off the centre of the ship domain. Coldwell (1983) set different sizes for the three areas depending on the circumstances in which the ship encounters other ships. However, recording the target ship's data for 
affecting domain size and shape is difficult (Pietrzykowski and Uriasz, 2009). The introduction of the automatic identification system (AIS) enables the recording of the data accurately (Robards et al., 2016; Szlapczynski and Szlapczynska, 2017). Based on these data, a number of marine safety-related studies have been conducted (Rawson et al., 2014) and used in ship domain studies (Silveira et al., 2013; Hörteborn et al., 2019). Therefore, many researchers have proposed ship's domains based on AIS data (Gucma and Marcjan, 2012; Hansen et al., 2013; Van Iperen, 2015; Hörteborn et al., 2019). Gucma and Marcjan (2012) developed a polygonal probabilistic domain based on AIS data for passing distance between ships. Hansen et al. (2013) and Van Iperen (2015) presented elliptical ship domain models using extensive movement data of the ship obtained using AIS. Hörteborn et al. (2019), however, presented a circle-shaped domain in crossing situations and an elliptical domain in overtaking situations.

The second type of ship domain model is one based on mathematical formulas. Kijima and Furukawa (2003) presented a ship domain model including a watching area and a blocking area based on mathematical formulas that use factors such as ship length, ship width and relative speed. Similarly, Liu et al. (2016) presented a dynamic domain that considered ship length, turning speed and time, in addition to other factors of ships operating in a restricted area.

The third type of ship domain model is classified as a model based on fuzzy logic. Therein, fuzzy logic is applied to determine the size of a domain according to the degree of danger. The first case of applying fuzzy logic to the ship domain was presented by Zhao et al. (1993), wherein fuzzy logic was applied to Goodwin's model to determine the vessel domain size using the distance of the closest point of approach (DCPA) and the time to the closest point of approach (TCPA). Subsequently, various ship domain studies were conducted using fuzzy logic. Pietrzykowski (2008), Pietrzykowski and Uriasz (2009) presented a model in which the size of the ship domain is determined on the basis of the safety navigation level.

Thus far, the majority of ship domain models have been studied using the above-mentioned approaches. However, the current models may have limitations for application in restricted areas. The statistics-based model uses ships' trajectories obtained using AIS and radar observation data. The design of this modelling is based on the distance between two ships passing by each other. However, it has a limitation in the sense of maintaining a safe distance. In a situation wherein a navigator wants to pass through a restricted area, spatial limitations might prevent them from maintaining enough distance between their ship and a relative one (Pietrzykowski, 2008).

In contrast, in the second type of modelling, because the formula-based domain is primarily based on ship parameters, many marine environmental factors must be considered (Wang, 2013). Finally, in the third type of modelling, the fuzzy domain has the advantage of being able to assess surrounding situations, unlike the other models (Im and Luong, 2019). However, often fuzzy domain models do not fully consider human and environmental factors (Wang, 2013). Furthermore, they are not considered universal models that are practical in any situation because most of them are developed based only on simulations of specific ship models (Wang et al., 2009).

Practical application of the existing models is difficult, given that there are too many parameters at sea that need to be considered. Moreover, even more parameters must be considered in restricted areas than in open water. Therefore, creating a practical domain reflecting all these factors would be impossible; hence, selecting the most important parameters among these factors is necessary. This can be achieved by examining the standards that seafarers use to define their own domains, the factors that play the most important role in seafarers' domains and factors that have not been considered in previous domain studies.

Thus far, ship domain research has primarily focused on preventing collisions of ships operated by humans (Pietrzykowski, 2008; Pietrzykowski and Uriasz, 2009; Szlapczynski and Szlapczynska, 2017; Szlapczynski et al., 2018). However, advances in the artificial intelligence (AI) research field have predicted the era of autonomous ships (MUNIN Project, 2016; IBM, 2020), and studies have been conducted on collision avoidance systems and collision risk assessment based on ship domain associated with autonomous ships (Kijima and Furukawa, 2003; Liu and Bucknall, 2015; Park and Kim, 2016; Szlapczynski and Szlapczynska, 2016; Wielgosz, 2017; Szlapczynski et al., 2018). Therefore, 
ship domain studies are an essential basic step for developing AI-based collision avoidance systems. Early AI research has surpassed human abilities by learning human action patterns (Wang et al., 2016). Therefore, a ship domain model used in autonomous ships may also need to be based on human action patterns. However, various existing domain models have been constructed exclusively on the basis of the navigator's knowledge and ability, despite the studies including a navigator's factor (Pietrzykowski, 2008; Wang, 2013).

The awareness of seafarers can be evaluated using an awareness value that is determined through interviews based on the situation awareness (SA) theory proposed by Endsley (1988). The SA theory was designed to prevent accidents that could occur as a result of mistakes made by humans engaged in dangerous work, such as nuclear power plant operators and air force pilots. According to the SA theory, SA is the perception of elements in an environment within a volume of time and space, the comprehension of their meaning, and projection of their status in the near future (Endsley, 1988). Hence, in this study, 125 seafarers were interviewed, including all ranks on merchant ships, to investigate the seafarers' awareness and understand their action patterns.

This study aims to show the difference between the existing domain models and domains that seafarers form based on their awareness. Then, a novel domain model will be proposed based on the seafarers' awareness. This will highlight the limitations of the previous models and the seafarers' awareness model. Furthermore, ship domains are typically classified into dangerous and safe domains; however, in the seafarers' awareness model, there are 'cautious' domains, that are neither dangerous nor safe. Additionally, this study attempts to determine the areas that are not included in both domains, i.e., the cautious distance between a seafarer's own ship and relative ships, as well as the SA mechanism through which the standard distance is created.

The rest of this paper is organised as follows. The methodology used is presented in Section 2. The analysis of the interview data is explained in Section 3. Section 4 presents the modelling of the awareness-based domain. In Section 5, an analysis of the proposed ship domain model and a comparison with other domain models are described. Finally, conclusions, including the limitations of the proposed model and future works, are presented in Section 6.

\section{Configuration of the awareness-based domain}

\subsection{Shape of ship domain}

Through many studies of ship domains, ship domains of various shapes, such as round, elliptical and polygonal, have been presented (Liu et al., 2016; Im and Luong, 2019). Each domain shape has certain advantages and disadvantages. Round and elliptical domains are convenient to design but may have limitations in expressing the degree of risk for navigation situations (Wang and Chin, 2016). In contrast, a polygonal domain would be good for assessing the degree of risk, but it is not easy to determine a polygonal domain unless the calibration is strict (Wang and Chin, 2016).

This study proposes an elliptical-shaped domain. Typically, specifically quantifying the awareness of the degree of risk for the ship's bearing is challenging for seafarers. Therefore, designing a polygonal domain may not be suitable for considering seafarers' awareness. Moreover, navigators show a tendency to perceive crossing situations as more dangerous than head-on and overtaking situations (Yim et al., 2018). Thus, a domain model must regard crossing situations in which other ships pass the fore or aft of the seafarer's own ship as more dangerous than head-on and overtaking situations. Hence, the elliptical shape is a more suitable design for a domain model based on longitudinal and lateral distances with relative ships passing in proximity to the seafarer's own ship.

Figure 1 shows three encountering situations: crossing, head-on and overtaking situations are assumed herein to determine the size of a ship domain. In the cases of head-on and overtaking situations, relative ships can pass by both sides of the seafarer's own ship, as shown in Figures 1(a) and 1(b). In a crossing situation, relative ships can pass the fore or aft of the seafarer's own ship from both the port and starboard sides, as shown in Figure 1(c). 
(a)

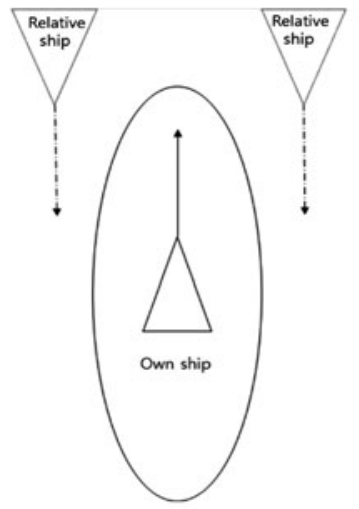

Head-on situation (b)

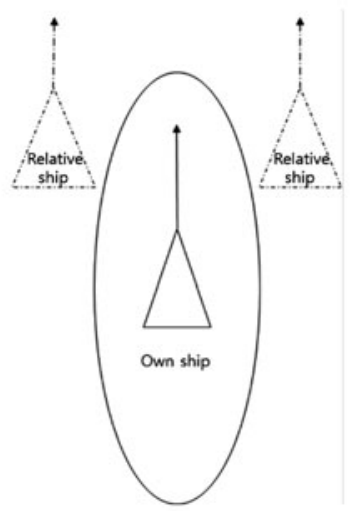

Overtaking situation (c)

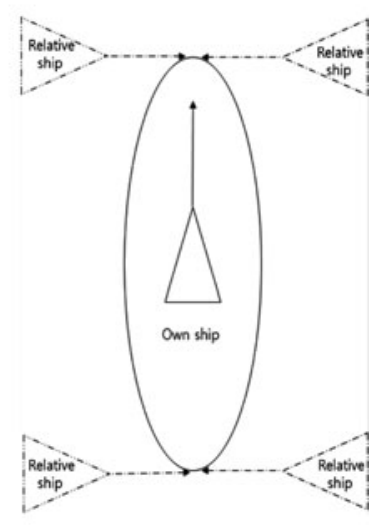

Crossing situation

Figure 1. Assumption of encounters with relative ships: (a) head-on situation, (b) overtaking situation, (c) crossing situation.

\subsection{Determining ship domain}

\subsubsection{Criteria for defining a restricted area}

To define a ship domain that is applicable in a restricted area, the criteria for defining the restricted area must be determined. Owing to the complicated characteristics of the maritime traffic environment, the definition of a restricted area is not clearly presented even in the International Regulations for Preventing Collisions at Sea (COLREGS). Establishing a clear definition of a restricted area that can be applied to all cases is difficult. Several countries had attempted to define such a restricted area but failed to reach an agreement (Allen, 2010). The general view is that a restricted area should be interpreted by considering the navigator's navigational customs, theories and precedents. In the case of a ship collision, the British Admiralty Court, most prominent in maritime trials, makes a decision while considering the customs of navigators in the area (Cockcroft and Lameijer, 2003).

In this study, the width of the restricted area was discussed among 14 senior-level seafarers, including captains and chief officers, and the range of the width of a channel was sufficiently set from 1 to $4 \mathrm{~nm}$. As described above, COLREGS does not define the width of the restricted area. Therefore, the authors decided to set it up from one mile after coordinating the opinions of the expert group through the preliminary investigation.

In addition, this study includes a traffic separation scheme (TSS), which includes detailed operational rules. Rules in the TSS are clearly stated for entry, departure and navigation areas in COLREGS. Therefore, two ships rarely meet each other on reciprocal courses in the TSS. However, nearly reciprocal courses are also considered for head-on situation (COLREGS, 1972). Degrees of nearly reciprocal courses are considered port and starboard, with the maximum of 3 degrees and a total of 6 degrees (Cockcroft and Lameijer, 2003). Further, the distance between two ships where navigation regulation for a head-on situation begins to be applied is uncertain; it may be 6 miles based on visibility of lights or more than 6 miles (Cockcroft and Lameijer, 2003). Therefore, considering these two factors for headon situations, such as nearly reciprocal courses and the distance at which navigation rules begin to be applied, a ship coming from the opposite traffic in the TSS can be also considered as a relative ship in head-on situations in this study. Thus, a restricted area is used in the same meaning as a narrow channel, narrow canal or narrow waterway in this research.

\subsubsection{Criteria for determining domain size}

DCPA and TCPA are important data for navigators to determine whether they are at risk (Iwasaki and Hara, 1986; Hasegawa and Kouzuki, 1987). DCPA is a concept of distance. For example, if the value 


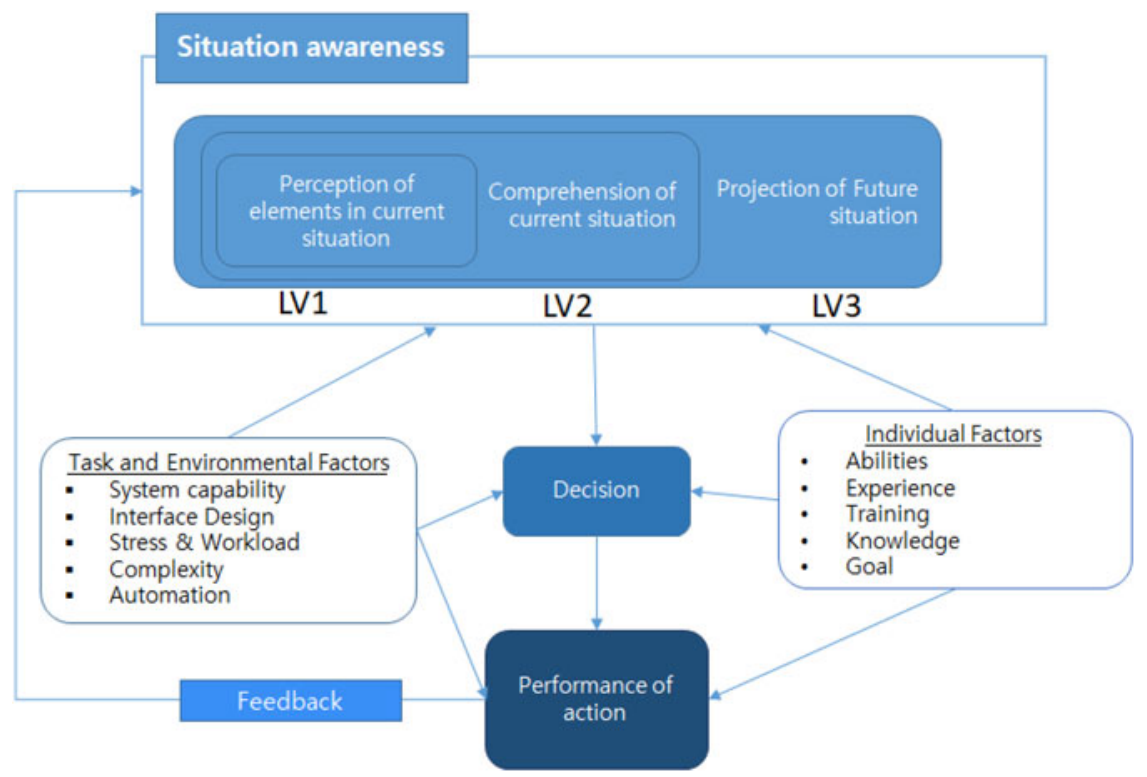

Figure 2. Diagram of theory of situation awareness.

of DCPA of a relative ship is very small and its TCPA value is large even for $30 \mathrm{~min}$, the navigator will keep monitoring the relative ship for $30 \mathrm{~min}$. Thus, for seafarers, DCPA is the factor that determines whether there is a collision risk, and TCPA is the factor that determines the timing of collision avoidance. Therefore, herein, the size of the domain will be defined based on the value of DCPA.

\subsection{Derivation of awareness value}

SA is defined as 'the perception of environmental elements and events with respect to time or space, the comprehension of their meaning and the projection of their future status' (Endsley, 1988). The SA theory was developed to prevent accidents caused by the failure of aircraft pilots (Endsley, 1995). Applying the SA theory to seafarers who sail in restricted areas enables them to be aware of the situation using several factors around them and determine whether they should be cautious of relative ships. The decision making can be performed according to the threshold value of DCPA among other extensive information. This study analyses how the threshold value of DCPA, which is used as a criterion for individual navigators and captains, was formed through the SA theory.

According to the SA theory, a person follows the mechanism of SA and accordingly decides to act. Figure 2 presents the three-step mechanism of SA, decision making and performance of action. The SA is analysed in three levels in particular. The application of each SA level to the seafarer's situation would be as follows. At level 1, a seafarer recognises DCPA information through a radar. Then, in level 2, they understand the current situation, such as a crossing or head-on situation, based on the information of relative ships. Finally, in level 3, the SA is finished by projecting what will happen in the near future.

Furthermore, experienced workers exhibit a higher level of SA and can accurately predict the future (Endsley, 1988; Endsley and Bolstad, 1994). Therefore, junior-level officers such as second and third officers, who do not have enough experience, would not possess good SA. Conversely, senior-class seafarers such as chief officers and captains would have a high level of SA because they have experienced the mechanisms shown in Figure 2 many times.

Figure 2 shows that SA is affected by individual and environmental factors as well as the feedback from the performance of action. In Figure 2, $\mathrm{SA}_{\mathrm{value}}$ is defined as the function of environmental 
Table 1. Sub-parameters of individual factors.

\begin{tabular}{lcl}
\hline Individual factors & Parameters & \\
\hline Knowledge $\left(\kappa_{n}\right)$ & $\kappa_{C}$ & COLREGS \\
& $\kappa_{M}$ & Own ship's manoeuvrability \\
& $\kappa_{P}$ & Phenomena occurring during navigation \\
Ability $\left(\alpha_{n}\right)$ & $\alpha_{I}$ & Innate ability \\
& $\alpha_{A}$ & Acquired ability \\
Experience $\left(\varepsilon_{n}\right)$ & $\varepsilon_{R}$ & Sailing in a restricted area \\
& $\varepsilon_{X}$ & Crossing situation \\
& $\varepsilon_{H}$ & Head-on situation \\
& $\varepsilon_{O}$ & Overtaking situation \\
& $\varepsilon_{I}$ & Irregular situation \\
& $\varepsilon_{C}$ & Sailing according to the condition of own ship \\
& $\varepsilon_{E}$ & Sailing in different natural conditions \\
& $\varepsilon_{A}$ & Accident and near-miss \\
Training $\left(\tau_{n}\right)$ & $\tau_{I}$ & Imagined training based on the ship's manoeuvrability table \\
& $\tau_{S}$ & Ship's simulator training \\
Goal $\left(\zeta_{n}\right)$ & $\zeta_{S}$ & Safety of navigation \\
& $\zeta_{O}$ & Safety of own ship \\
\hline
\end{tabular}

factors $\left(\mathrm{SA}_{\mathrm{EF}}\right)$, individual factors $\left(\mathrm{SA}_{\mathrm{IF}}\right)$ and the feedback from the performance of action $\left(\mathrm{SA}_{\mathrm{FB}}\right)$ as follows.

$$
\mathrm{SA}_{\mathrm{value}}=f\left(\mathrm{SA}_{\mathrm{IF}}, S \mathrm{~A}_{\mathrm{EF}}, S \mathrm{~A}_{\mathrm{FB}}\right)
$$

As shown in Equation (1), the $\mathrm{SA}_{\mathrm{value}}$ will be formed by considering $\mathrm{SA}_{\mathrm{IF}}, \mathrm{SA}_{\mathrm{EF}}$ and $\mathrm{SA}_{\mathrm{FB}}$ of the seafarer's individual performance of action. Seafarers can have various $\mathrm{SA}_{\text {value }}(\mathrm{s})$. According to COLREGS Rule 5, the officer on watch (OOW) must use all means, including visual and auditory, to understand the situation. For example, the value of sound can also be the $\mathrm{SA}_{\text {value }}$. Through the sound of hull vibrations, navigators can determine the condition of their ship's engine. Additionally, in foggy conditions, officers can determine the location of a relative ship by the sound of its whistle. The threshold value of DCPA is also one of several SA values required for understanding a situation, as shown in Equation (2).

$$
\mathrm{SA}_{\text {value }} \ni \mathrm{DCPA}_{\mathrm{TV}}
$$

DCPA threshold value in nautical miles $\left(\mathrm{DCPA}_{\mathrm{TV}}\right)$ is formed through individual factors, environmental factors and feedback of the action performed during sailing. However, an individual's situational awareness may vary according to their individual factors (Endsley, 1988). Hence, the $\mathrm{DCPA}_{\mathrm{TV}}$, which is the standard of caution for each individual seafarer, would be different. Based on the individual factors presented in Figure 2, individual factors were subdivided into detailed items, as shown in Table 1.

Table 1 shows the elements that could be in $\mathrm{SA}_{\mathrm{IF}}$. The factor $\kappa_{n}$ represents the seafarer's knowledge, including three components: $\kappa_{C}, \kappa_{M}$ and $\kappa_{P}$. Parameter $\kappa_{C}$ is the knowledge of COLREGS, the most basic knowledge of navigation for ships. Parameter $\kappa_{M}$ is the knowledge of the manoeuvrability of ship on board which the interviewee works. The values of various manoeuvring performances of the boarding ship according to the standards of the International Maritime Organization are presented as figures according to the loading conditions of the ship. Parameter $\kappa_{P}$ is the knowledge of physical phenomena that can occur around the seafarer's own ship during sailing.

Factor $\alpha_{n}$ represents personal ability. Parameter $\alpha_{I}$ is an innate ability and $\alpha_{A}$ is an acquired one. Factor $\varepsilon_{n}$ represents personal experience. Parameter $\varepsilon_{R}$ is the experience of sailing in a restricted area, and $\varepsilon_{X}, \varepsilon_{H}$ and $\varepsilon_{O}$ are the experiences of crossing, head-on and overtaking situations, respectively. 
Parameter $\varepsilon_{I}$ is the experience of irregular situations that can occur during a voyage. Examples include ships that are sailing in violation of the law and breakdowns of navigational equipment, such as failure of autopilot while sailing. Parameter $\varepsilon_{C}$ is the experience of operation according to the condition of the boarding ship. According to the loading condition of the ship, the draft is significantly different, and hence the manoeuvring performance is also different. Therefore, seafarers must consider this as well. Parameter $\varepsilon_{E}$ represents sailing experience in various natural situations including various bearings and speeds of the current, wind and visibility. Parameter $\varepsilon_{A}$ represents accidents and near-miss experiences during voyage.

Factor $\tau_{n}$ represents training. Parameter $\tau_{I}$ is image training on how to cope with assumed situations, and $\tau_{S}$ is ship-handling training through a simulator.

Factor $\zeta_{n}$ represents a goal. Parameters $\zeta_{S}$ and $\zeta_{O}$ represent safety of navigation and safety of the seafarer's own ship. Parameter $\zeta_{O}$ can be strongly applied to the ship's captain.

The relation between individual factors $\mathrm{SA}_{\mathrm{IF}}$ and the elements shown in Table 1 is expressed in Equation (3).

$$
\mathrm{SA}_{\mathrm{IF}}=f\left(\kappa_{n}, \alpha_{n}, \varepsilon_{n}, \tau_{n}, \zeta_{n}\right)
$$

These various factors constitute the value of $\mathrm{DCPA}_{\mathrm{TV}}$, which is a seafarer's own threshold value of DCPA. Based on these factors, seafarers will judge, act upon and repeat the SA mechanism several times, accepting feedback on their performance. Therefore, they will have their own DCPA .

To measure the DCPA various ways of SA measurement. This method involves asking workers about their SA in a direct manner; this method has an obvious disadvantage in the sense that the workers' answers are subjective (Endsley and Garland, 2000). However, considering the working environment of a seafarer, it was chosen as the most realistic method for measuring the SA values. The authors interviewed 125 seafarers, including a pilot, and asked them when they start being cautious of a relative ship of the DCPA $\mathrm{TV}_{\mathrm{TV}}$ in restricted area. The situation is investigated by presenting three navigation situations in which a relative ship passes by the seafarer's own ship, as shown in Figure 1.

\section{Interview data}

\subsection{Interview-related matters}

The characteristics of awareness values were analysed through $\mathrm{SA}_{\mathrm{IF}}$ in the SA theory. Interviews were conducted as follows.

- Period of interviews: February 2020-March 2020

- Questions

- In three encounter situations such as crossing, head-on and overtaking situations, what is your DCPA $_{\mathrm{TV}}$ when you start becoming cautious of a relative ship? (Caution implies that the threshold value of DCPA is not large enough to avoid the relative ship but also not small enough to be careless.)

- What is the reason and background for having your own $\mathrm{DCPA}_{\mathrm{TV}}$ ?

- In a crossing situation, do you change the DCPA threshold value according to the relative bearings of the target ship?

- In crossing situations, which is safer, the target ship passing in front of own ship or behind it? (This question is asked to only the 14 senior-class members to establish the domain shape.)

- Interview method: online

- Interviewee selection method: co-workers who worked with one of the authors and navigators who were students of one of the authors. 
Table 2. Classification based on boarding ship's type.

\begin{tabular}{lcc}
\hline Type of Ship & Number & Percentage \\
\hline Bulk carrier & 29 & $23 \cdot 6 \%$ \\
LNG carrier & 23 & $18 \cdot 7 \%$ \\
LPG carrier & 11 & $8 \cdot 9 \%$ \\
VLCC & 7 & $5 \cdot 7 \%$ \\
Chemical tanker & 12 & $9 \cdot 8 \%$ \\
Car carrier & 5 & $4 \cdot 1 \%$ \\
Container carrier & 17 & $13 \cdot 8 \%$ \\
ETC & 19 & $15 \cdot 4 \%$ \\
Total & 123 & $100 \%$ \\
\hline
\end{tabular}

The interviewees included 110 navigators, 15 captains sailing on the oceans, and one pilot. However, the $\mathrm{DCPA}_{\mathrm{TV}}$ of one captain was excluded because he had less than two months of experience as a captain. According to the SA theory, SA is formed through performing and feedback from work (Endsley, 1988; Endsley and Bolstad, 1994). Inferring how long should be the period it takes to form SA values is not possible in this paper, but the authors decided that his experience as a captain was not enough for this research. One value of a navigator was also excluded because he worked on a fishing guidance ship that was close to fishing boats; hence, his DCPA threshold value was very small compared with other navigators.

Table 2 shows the types of ship on which the interviewees worked. It shows the distribution of various ships.

The SA values may vary depending on the ship's speed, so the interview was conducted based on the interviewee's ship's normal speed of sailing in restricted areas.

\subsection{Discussion}

The number of samples in this study was a concern for the authors. It would be preferable to have more data. Due to the occupational conditions of seafarers, however, the data presented in this study were the maximum it was possible to obtain. Although the data presented in this study may not be statistically perfect, the authors think that DCPA threshold values presented by more than 120 samples are somewhat meaningful.

The seafarers had their own $\mathrm{DCPA}_{\mathrm{TV}}$ as follows. Third officers responded that they themselves lacked experience and therefore had values based on theoretical backgrounds such as COLREGS or precedent cases. Chief and second officers responded that they usually had their own DCPA $_{\mathrm{TV}}$ based on their own experiences although individual differences were present. Captains considered many aspects because they are the ship owner's representatives and know their social responsibilities well. They have higher DCPA $_{\mathrm{TV}}$ than navigators.

\subsection{Results of interview data}

Figure 3 shows the distribution of $\mathrm{DCPA}_{\mathrm{TV}}$ of 123 seafarers. In the figure, the horizontal axis represents the length of the vessel on board which the seafarers work, and the vertical axis shows the DCPATV. The green symbols represent the values for crossing situations, black symbols represent head-on situations and pink symbols represent overtaking situations. Overall, the values for crossing situations are relatively larger than the values for the rest of the encounter situations. The maximum value of DCPA $\mathrm{TV}_{\text {for }}$ crossing situations is 2 nautical miles. Further, the values for overtaking situations are the lowest, and the values for head-on situations are somewhat higher than those of overtaking situations. Figure 3 


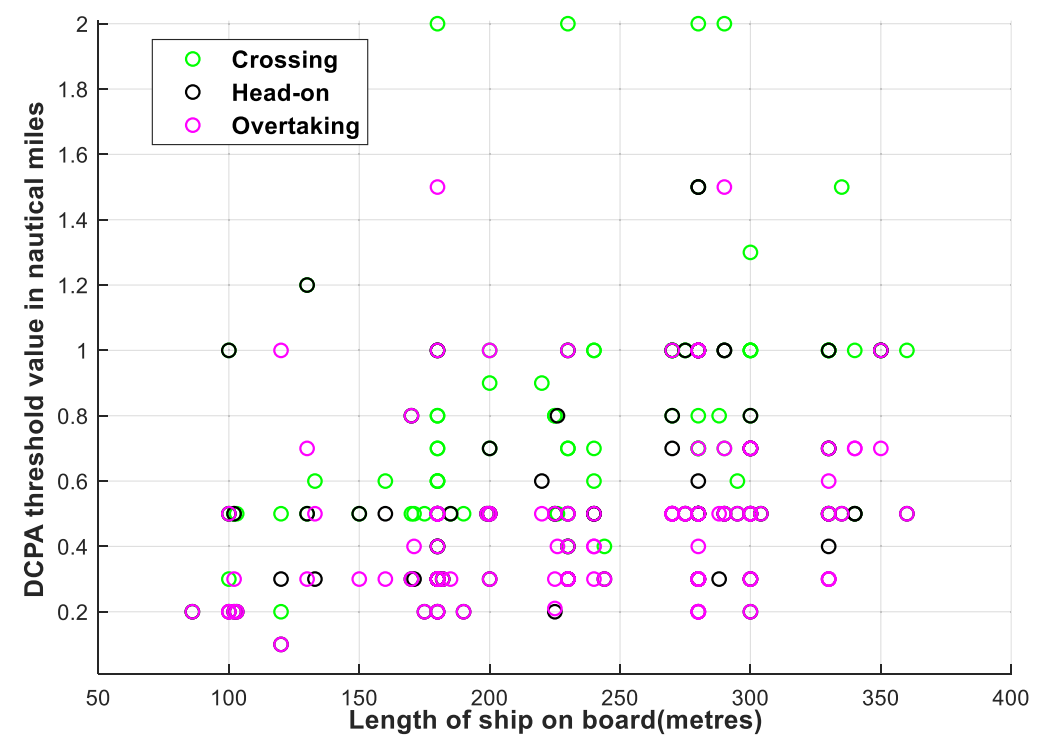

Figure 3. Distribution of awareness values.

Table 3. Ship operator's non-dimensional DCPA $A_{T V}$.

\begin{tabular}{lcccccc}
\hline Rank & $\begin{array}{c}\text { Number in } \\
\text { sample }\end{array}$ & $\begin{array}{c}\text { Rank } \\
\text { code }\end{array}$ & $\begin{array}{c}\text { Average } \\
\text { length }(L) \\
(\mathrm{m})\end{array}$ & $\frac{\mathrm{DCPA}_{\mathrm{TV}}^{C}}{L}$ & $\frac{\mathrm{DCPA}_{\mathrm{TV}}^{H}}{L}$ & $\frac{\mathrm{DCPA}_{\mathrm{TV}}^{O}}{L}$ \\
\hline Captain and Pilot & 14 & $S_{1}$ & 278 & $7 \cdot 76$ & $4 \cdot 57$ & $4 \cdot 19$ \\
Chief officer & 38 & $S_{2}$ & 238 & $5 \cdot 32$ & $4 \cdot 01$ & $3 \cdot 24$ \\
Second officer & 36 & $S_{3}$ & 236 & $5 \cdot 56$ & $3 \cdot 75$ & $3 \cdot 51$ \\
Third officer & 35 & $S_{4}$ & 229 & $6 \cdot 01$ & $4 \cdot 27$ & $4 \cdot 28$ \\
Total & 123 & $\sum S$ & 240 & $5 \cdot 89$ & $4 \cdot 08$ & $3 \cdot 72$ \\
\hline
\end{tabular}

shows that the length of the ship is not so relevant to the formation of the $\mathrm{DCPA}_{\mathrm{TV}}$, revealing a slightly different aspect from existing domain studies (Kijima and Furukawa, 2003; Wang, 2010; Liu et al., 2016; Im and Luong, 2019). Hence, a more detailed analysis is required in this regard.

The $\mathrm{DCPA}_{\mathrm{TV}}(\mathrm{s})$ obtained through the interviews are the awareness values of seafarers, and the values for the three encountering situations are distinguished as DCPA threshold value of a head-on situation $\left(\mathrm{DCPA}_{\mathrm{TV}}^{H}\right)$, DCPA threshold value of an overtaking situation $\left(\mathrm{DCPA}_{\mathrm{TV}}^{O}\right)$ and DCPA threshold value of a crossing situation $\left(\mathrm{DCPA}_{\mathrm{TV}}^{C}\right)$. The unit of the values is the nautical mile. However, these DCPA $\mathrm{TV}_{\mathrm{TV}}$ values cannot be compared with each other directly as the lengths of the ships vary across the interviewed seafarers. Thus, to analyse $\mathrm{DCPA}_{\mathrm{TV}}$, they must be expressed by non-dimensional values. The average $\mathrm{DCPA}_{\mathrm{TV}}$ of each rank of interviewees is divided by the average length of their vessels $(L)$ and expressed as a non-dimensional value.

Table 3 shows the non-dimensional $\mathrm{DCPA}_{\mathrm{TV}}$ of each rank of interviewees. the differences in the values between ranks and what affected the formation of perceived values of seafarers were analysed through the SA theory.

As shown in Table 3, the non-dimensional $\mathrm{DCPA}_{\mathrm{TV}}$ for $S_{1}$ (captain) is the largest among the groups based on rank. Prior to the interview, it was expected that the $\mathrm{DCPA}_{\mathrm{TV}}$ for $S_{1}$ with the most navigational experience would be the smallest owing to the limitation of space in restricted areas. However, the values 
Table 4. Non-dimensional $D C P A_{T V}$ and $D C P A_{T V}$ depending on the boarding ship's length.

\begin{tabular}{|c|c|c|c|c|c|c|c|c|}
\hline \multirow[b]{2}{*}{ Group } & \multirow[b]{2}{*}{$\begin{array}{l}\text { Length } \\
(L)(\mathrm{m})\end{array}$} & \multirow{2}{*}{$\begin{array}{l}\text { Average } \\
\text { length } \\
(L)\end{array}$} & \multicolumn{3}{|c|}{ Non-dimensional } & \multicolumn{3}{|c|}{ Nautical mile } \\
\hline & & & $\frac{\mathrm{DCPA}_{\mathrm{TV}}^{C}}{L}$ & $\frac{\mathrm{DCPA}_{\mathrm{TV}}^{H}}{L}$ & $\frac{\mathrm{DCPA}_{\mathrm{TV}}^{O}}{L}$ & $\mathrm{DCPA}_{\mathrm{TV}}^{C}$ & $\mathrm{DCPA}_{\mathrm{TV}}^{H}$ & $\mathrm{DCPA}_{\mathrm{TV}}^{O}$ \\
\hline$L_{1}$ & 0-199 & 157 & $7 \cdot 05$ & $5 \cdot 00$ & $4 \cdot 90$ & $0 \cdot 60$ & 0.42 & $0 \cdot 42$ \\
\hline$L_{2}$ & $200-299$ & 259 & 5.93 & $4 \cdot 10$ & $3 \cdot 60$ & $0 \cdot 83$ & 0.57 & $0 \cdot 50$ \\
\hline$L_{3}$ & $300-350$ & 320 & 4.94 & $3 \cdot 33$ & $3 \cdot 06$ & 0.85 & 0.58 & 0.53 \\
\hline
\end{tabular}

exhibited an opposite tendency. The interviews have shown that $S_{1}$ tends to be more concerned about accidents that may occur in the same situation and seafarers of this rank replied that they would avoid danger in advance by setting the $\mathrm{DCPA}_{\mathrm{TV}}$ to be bigger. The $\varepsilon_{A}$ of the SA elements was thus reflected. If so, the non-dimensional DCPA $\mathrm{TV}_{\mathrm{TV}}$ for $S_{2}$ (chief officer) should be greater than that for $S_{4}$ (third officer), but it is not; hence, it can be expected that other factors are in play. $S_{2}$ and $S_{1}$ are differentiated by $\varepsilon_{n}$, but the biggest difference is observed with respect to $\zeta_{n}$. The purpose of $S_{1}$ is to sail the ship safely without accident. Of course, the OOW is also responsible for safety during navigation, but the weight of the responsibilities of the navigators is different from that of captains. The captain's responsibility is specified in the international convention: the captain has full responsibility for the ship according to the International Safey Management Code. This is why the values of $\zeta_{n}$ of captains are much bigger than those of navigators. Therefore, the characteristics of non-dimensional DCPA $\mathrm{TV}_{\mathrm{TV}}$ for $S_{1}$ depend on the $\zeta_{n}$, resulting in a higher DCPA threshold value than those of $S_{2}, S_{3}$ and $S_{4}$.

Among the navigators, the dimensional value for $S_{4}$ is the largest. During the interview, $S_{4}$ stated that the cause of the difficulty and fear of sailing in encounter situations with relative ships is the lack of $\kappa_{n}$ and $\varepsilon_{n}$. Hence, they operate ships with a large DCPA $A_{\mathrm{TV}}$. The value of $S_{2}$ was smaller than $S_{3}$ (second officer) except for non-dimensional $\mathrm{DCPA}_{\mathrm{TV}}^{H} \cdot S_{2}$ stated that the recognition value was small because of their experience. They stated that the experience of avoiding relative ships even at a distance closer than expected was significant. And the non-dimensional $\mathrm{DCPA}_{\mathrm{TV}}^{C}$ is the highest among the values. Thus, the ship operators are the most burdened by crossing situations in restricted areas.

There is one factor in seafarers that will have the greatest impact on recognition values. To find that factor, the groups based on rank were divided according to the lengths of their vessels. This is because many studies have constructed the domain size based on ship size (Kijima and Furukawa, 2003; Wang, 2010; Szlapczynski and Szlapczynska, 2017; Im and Luong, 2019).

The new groups included three categories based on the lengths of the interviewees' vessels. As there were almost no ships under $100 \mathrm{~m}$, the first group $\left(L_{1}\right)$ included lengths of $0-200 \mathrm{~m}$, the second group $\left(L_{2}\right)$ included lengths of $200-300 \mathrm{~m}$ and the third group $\left(L_{3}\right)$ included lengths of $300-350 \mathrm{~m}$, which is the maximum ship size. The length of the vessel can affect the seafarer's $\mathrm{DCPA}_{\mathrm{TV}}$ by changing factors such as $\kappa_{P}, \varepsilon_{C}$ and $\kappa_{M}$.

Table 4 shows the DCPA dimensional forms. Unexpectedly, the non-dimensional DCPA is the largest. Thus, through comparison with the dimensional values, we observe that the greater the length of the ship, the greater the $\mathrm{DCPA}_{\mathrm{TV}}$; however, this is not in proportion with the increase in the ship's length.

Next, to find out what main factors affect the $\mathrm{DCPA}_{\mathrm{TV}}$, the types of ships are analysed. Because ships have the proper shape or speed for transportation purposes, $\kappa_{M}$ varies considerably from one type of ship to another.

The distribution of ships on which the interviewees worked varies, as shown in Table 2, and among them, the types of ship's groups with the best and the worst $\kappa_{M}$ are classified as shown in Table 5. A ship's turning ability is influenced by the block coefficient $\left(C_{b}\right)$. Thus, four boarding ships were 
Table 5. Comparison of non-dimensional DCPA $A_{T V}$ between boarding ship groups.

\begin{tabular}{llcccccc}
\hline \multirow{2}{*}{ Group } & Type of ship & Length $(L)$ & Speed & $\frac{D C P A_{T V}^{C}}{L}$ & & $\frac{D C P A_{T V}^{H}}{L}$ & $\frac{D C P A_{T V}^{O}}{L}$ \\
\hline$T_{1}$ & Bulk/VLCC & 264 & $12-14 \mathrm{kts}$ & $6 \cdot 24$ & & $4 \cdot 17$ & $4 \cdot 33$ \\
$T_{2}$ & Container/LNG & 280 & $17-19 \mathrm{kts}$ & $5 \cdot 44$ & $3 \cdot 72$ & $3 \cdot 01$ \\
\hline
\end{tabular}

divided into two groups: $T_{1}$, comprising bulk carriers $\left(C_{b}: 0.80--0.86\right)$ and Very Large Crude Carrier (VLCC) $\left(C_{b}: 0.81--0.82\right)$, in which ships have a high value of $C_{b}$ and $T_{2}$, comprising liquid natural gas (LNG) carriers $\left(C_{b}: 0.72--0.75\right)$ and container carriers $\left(C_{b}: 0.60--0.72\right)$, in which ships have smaller $C_{b}$ values (Ha and Gourlay, 2017).

Table 5 shows that $\kappa_{M}$ can be the most important factor in the formation of awareness values for a seafarer. $\kappa_{M}$ includes the course changing ability. This factor is important because ships mainly use a rudder to change their heading to avoid dangerous situations. Thus, Table 5 compares $\kappa_{M}$ 's superior group $\left(T_{1}\right)$ and $\kappa_{M}$ 's inferior group $\left(T_{2}\right)$. The DCPA $\mathrm{TV}_{\mathrm{TV}}$ shows that the value of $T_{1}$ with the larger $L$ and the faster speed is smaller than the value of $T_{2}$. This may be different from previous studies. Thus far, studies have set the size of the domain to be large if the length of the ship is large or the ship's speed is high. However, Table 5 indicates that $\kappa_{M}$ affects recognition values the most rather than speed and vessel size. Therefore, $\kappa_{M}$ has the greatest effect on the seafarers' $\mathrm{DCPA}_{\mathrm{TV}}$.

\subsection{Analysis of interview data}

Through the analysis of the interview data, the following three factors can be found. The first factor is that although the number of captains interviewed was small, the values of the captains were the highest when compared with the entire group, owing to $\zeta_{n}$. This is attributed to the captain's responsibility of representing the ship owner. The second factor is that in the navigators' group, overall, the $\operatorname{DCPA}_{\mathrm{TV}}(\mathrm{s})$ decrease as the navigators' ranks increase. This can be attributed to the difference in experience $\left(\varepsilon_{n}\right)$. The factor that varies the greatest among ranks is the experience that results from time spent at sea. All interviewees were trained for the same four years at university, and in practice they underwent the same compulsory training and education after university for working on board as navigators. Therefore, the biggest reason for the difference in $\mathrm{DCPA}_{\mathrm{TV}}(\mathrm{s})$ between the groups seems to be $\varepsilon_{n}$. The third factor is that $\mathrm{DCPA}_{\mathrm{TV}}$ is more affected by the manoeuvrability of the ship $\left(\kappa_{M}\right)$, and not by the physical aspects of the ship, such as speed or length. Ships have different sizes, speeds and manoeuvrability depending on their type. Hence, to investigate how the type of ships affects DCPA $\mathrm{TV}_{\mathrm{TV}}$, two groups of ships of considerably different manoeuvrability are analysed.

Thus, the three most influential factors in the $\mathrm{DCPA}_{\mathrm{TV}}$ would be $\zeta_{n}, \varepsilon_{n}$ and $\kappa_{M}$. The SA theory generally argues that repeated experiences improve the workers' competence. As a result of the analysis, sailing experience based on the ship's manoeuvrability can be regarded as repeated experience in the navigator group. However, the captains' values showed a different tendency from the navigator group. This can be attributed to the emotional element of the captain being responsible for the ship.

Through the interviews, it can be confirmed that the awareness value of the seafarer's cautious area exists. This study attempted to obtain $\mathrm{DCPA}_{\mathrm{TV}}$ for every angle of the encountering ship, but the seafarers responded that $\mathrm{DCPA}_{\mathrm{TV}}$ values cannot be applied differently depending on the relative bearing of each target ship encountered in the traffic jam in a restricted area. This is because they are constantly busy judging and taking action. They also stated that setting up DCPA angle of the relative ships is challenging because the size of the ships in operation can be over $200 \mathrm{~m}$, which is too large for micro control. This is also a limitation of the present study, a limitation based on human awareness. Namely, seafarers judge the situation by categorising the encounter situation as a head-on, crossing or overtaking situation, and decide the caution area with the other vessel on a 


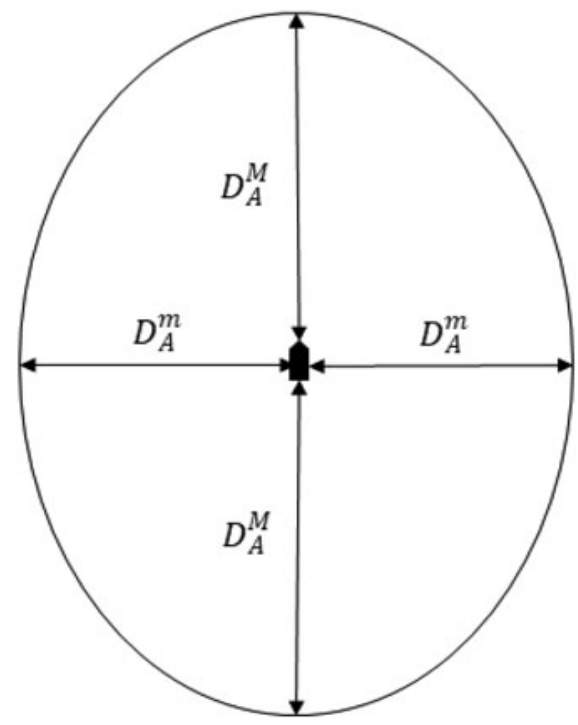

Figure 4. Composition diagram of $D_{A}$.

corresponding basis. The seafarer's threshold recognition value is not very detailed for every angle, but that does not mean that it does not exist. Although seafarers have different criteria, there are threshold values based on the SA theory.

\section{Awareness-based domain}

Through the interviews, specific values were obtained to create a seafarer's awareness-based domain. The $\mathrm{DCPA}_{\mathrm{TV}}$ for crossing situation, $\mathrm{DCPA}_{\mathrm{TV}}^{C}$, is suitable to define the front and rear lengths of the awareness-based domain $\left(D_{A}\right)$. The length of the minor axis of $D_{A}$ can be composed of DCPA $A_{\mathrm{TV}}$ for head-on situation, i.e., $\mathrm{DCPA}_{\mathrm{TV}}^{H}$. The $\mathrm{DCPA}_{\mathrm{TV}}$ for overtaking situation, $\mathrm{DCPA}_{\mathrm{TV}}^{O}$, can be used to define the length of the minor axis of $D_{A}$, but $\mathrm{DCPA}_{\mathrm{TV}}^{H}$ is greater than $\mathrm{DCPA}_{\mathrm{TV}}^{O}$. Therefore, it was decided to use DCPA ${ }_{\mathrm{TV}}^{H}$ for safety. Equations (4) and (5) define the size of $D_{A}$ :

$$
\begin{aligned}
D_{A}^{M} & =\frac{\mathrm{DCPA}_{\mathrm{TV}}^{C}}{L} \\
D_{A}^{m} & =\frac{\mathrm{DCPA}_{\mathrm{TV}}^{H}}{L}
\end{aligned}
$$

where $D_{A}^{M}$ and $D_{A}^{m}$ are the lengths of the major and minor axes of $D_{A}$, and $L$ represents the ship's length.

Although the shape of the domain model was set to be elliptical, experts' opinions were sought on whether it should be an asymmetric elliptical shape. This is because some senior-level seafarers argued that target ships passing in front of their own ship in crossing situations were dangerous. Others, however, had contrary opinions. They asserted that ships passing behind their own ship were more dangerous. For this reason, the domain model has the same length on both fore and aft sides, as shown in Figure 4.

Figure 5(a) shows an awareness-based domain for each rank. Before constructing the awarenessbased domain $D_{A}$, the domains of every rank were visualised through the averages of the $D_{A}^{M}$ and $D_{A}^{m}$ values of each rank. Although a large sample size of captains would be necessary for a more statistically significant comparison, the individual captain's domain substantially differs from all others. Conversely, the variation among navigators' domains is not as large. 
(a)

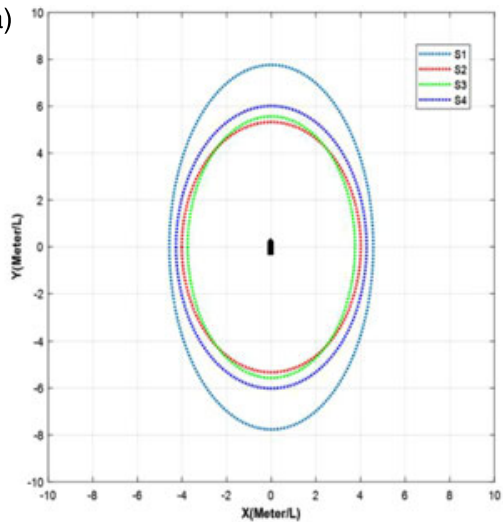

Domain by each rank

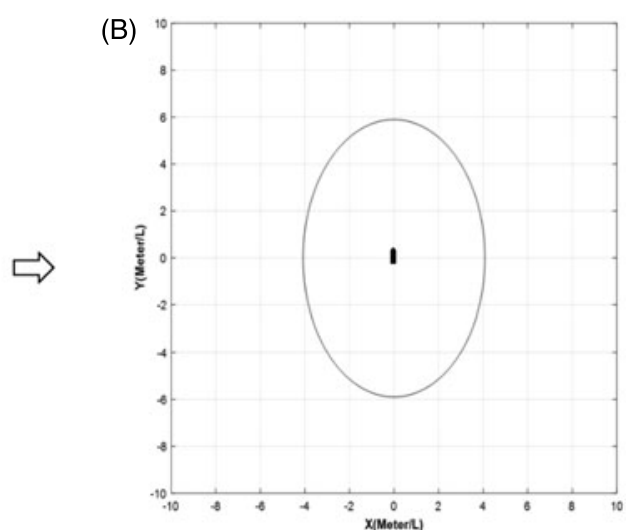

$\mathrm{D}_{A}$

Figure 5. Procedure of modelling $D_{A}$. (a) Average size of awareness-based domain by each rank. (b) Seafarer's awareness-based domain $\left(D_{A}\right)$.

Based on the values of all 123 seafarers, the seafarer awareness-based domain $D_{A}$ is presented in Figure 5(b). The values of $D_{A}^{M}$ and $D_{A}^{m}$ can be expressed as shown in Equations (6) and (7).

$$
\begin{aligned}
D_{A}^{M} & =\frac{\sum_{i=1}^{4} \sum_{j=1}^{S_{i}}\left(\mathrm{DCPA}_{\mathrm{TV}}^{C} / L\right)_{i, j}}{\sum_{i=1}^{4} S_{i}} \\
D_{A}^{m} & =\frac{\sum_{i=1}^{4} \sum_{j=1}^{S_{i}}\left(\mathrm{DCPA}_{\mathrm{TV}}^{H} / L\right)_{i, j}}{\sum_{i=1}^{4} S_{i}}
\end{aligned}
$$

where $S_{i}$ is the rank of the seafarers, $i$ is seafarers' group, $j$ is the person in the $i$-th group and $\left(\mathrm{DCPA}_{\mathrm{TV}} / L\right)_{i, j}$ is the $\mathrm{DCPA}_{\mathrm{TV}} / L$ of the $j$-th person belonging to $i$-th group.

\section{Analysis}

\subsection{Comparison with other domain models}

Many studies have been conducted on elliptical domains. In this study, the models that are applicable in restricted areas were selected to compare with the proposed $D_{A}$ model. Figure 6 shows comparisons between several elliptical domain models that are applicable to restricted areas, and Table 6 shows the details of the models. In the figure, the horizontal axis represents the port and starboard sides of the seafarer's own ship, and the vertical axis shows the front and back sides. The green line indicates Fujii's model (1971), red represents Coldwell's overtaking model (1983), pink represents Coldwell's head-on model (1983), sky blue represents Hansen's model (2013) and black represents the awareness-based domain $D_{A}$ proposed herein.

The value of $D_{A}^{M}$ is not much different from the length of the major axes of other elliptical models. It has almost the same value as the above-mentioned former two models (Fujii's and Coldwell's), and it has a difference of 2.0 L from Hansen's model. As for the value of $D_{A}^{m}$, the proposed model shows a moderate size. It is smaller than Coldwell's head-on situation model and larger than Hansen's model.

Compared with Hansen's model, the proposed model has a maximum difference of $2.0 \mathrm{~L}$. Assuming $L$ is $240 \mathrm{~m}$, which is the average length of the interviewees' ships, $2 \cdot 0 \mathrm{~L}$ corresponds to about $0 \cdot 26$ miles. In the open sea, 0.26 miles may not be a large distance, but it is about $34 \%$ of the average value of awareness in a restricted area. This difference needs to be studied further. 


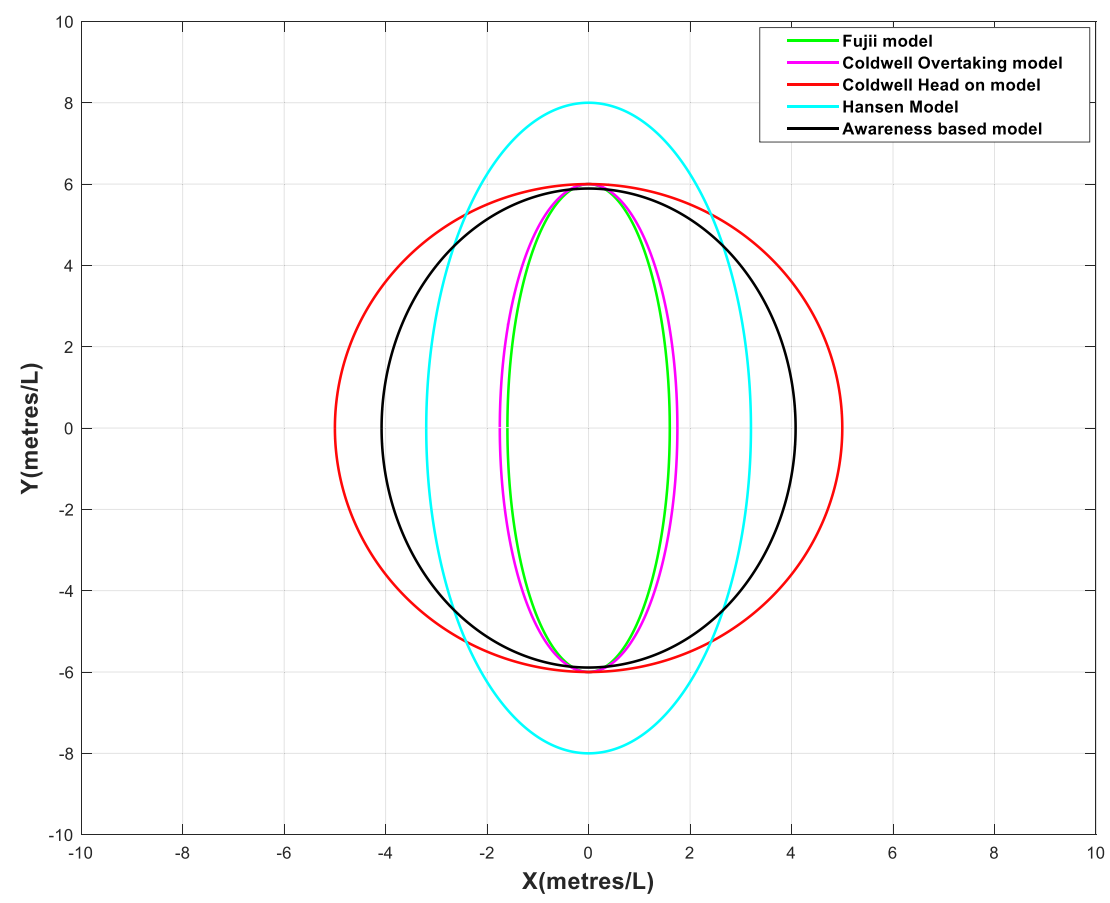

Figure 6. Ship domain model comparison.

Table 6. Values of $D_{A}^{M}$ and $D_{A}^{m}$ compared with other ship domain models.

\begin{tabular}{|c|c|c|c|c|}
\hline Model & Shape & $\begin{array}{c}\text { Length } \\
\text { (major/ } \\
\text { minor axes) }\end{array}$ & $\begin{array}{c}\text { Applicable } \\
\text { area }\end{array}$ & Method \\
\hline Fujii & Ellipse & $6 \cdot 0 L / 1 \cdot 6 L$ & $\begin{array}{l}\text { Open sea and } \\
\text { restricted area }\end{array}$ & Statistical method \\
\hline $\begin{array}{l}\text { Coldwell (Crossing and } \\
\text { Head-on) }\end{array}$ & Ellipse & $6 \cdot 0 L / 5 \cdot 0 L$ & Restricted area & Statistical method \\
\hline Coldwell (Overtaking) & Ellipse & $6 \cdot 0 L / 1 \cdot 75 L$ & Restricted area & Statistical method \\
\hline Hansen & Ellipse & $8 \cdot 0 L / 3 \cdot 2 L$ & Restricted area & Statistical method \\
\hline Kijima and Furukawa & Ellipse & Flexible & All area & Formula \\
\hline Pietrzykowski (2008) & Ellipse & Flexible & Restricted area & Fuzzy logic \\
\hline $\begin{array}{l}\text { Awareness-based } \\
\text { domain proposed in } \\
\text { this study }\end{array}$ & Ellipse & $5 \cdot 9 L / 4 \cdot 1 L$ & Restricted area & Awareness \\
\hline
\end{tabular}

\subsection{Discussion}

The purpose of this study is to present a domain model to determine danger and safety areas. DCPA $\mathrm{TV}_{\mathrm{TV}}$ was used to present the cautious domain, which is the intermediate area as shown in Figure 7. The rationale for the proposed model is that COLREGS Rule 8 states that collision avoidance should be performed from a safe distance, which is not specified. Considering the difficulty of navigating in restricted areas (Inoue, 2000) owing to spatial limitations, defining a safe distance is difficult. For example, avoiding a relative ship with a large $\mathrm{DCPA}_{\mathrm{TV}}$ is impossible because of the geographical limitations in restricted 


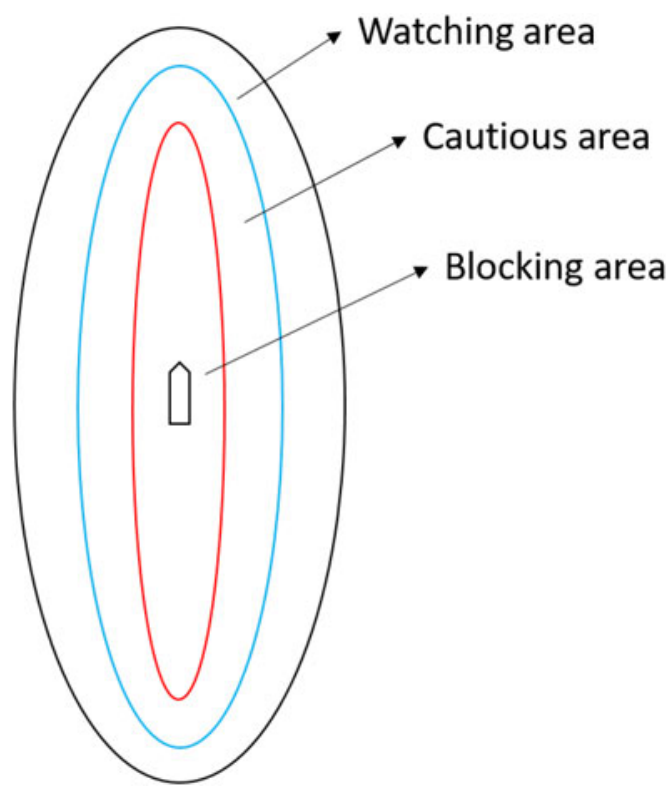

Figure 7. Concept of a novel ship's domain.

areas. Hence, practical DCPA $\mathrm{TV}_{\mathrm{TV}}$ values for COLREGS Rule 8 should be presented. To present the values, the middle area between danger and safety areas was materialised based on the $\mathrm{DCPA}_{\mathrm{TV}}$ values. At $\mathrm{DCPA}_{\mathrm{TV}}$, the navigators do not yet act upon collision avoidance against the target ship. This means that the middle area is more realistic than the safe area and safer than the dangerous area when it comes to collision avoidance behaviour.

Therefore, this study suggests cautious areas between the areas where action is taken and areas where no action is taken with reference to the concepts of the blocking and watching areas of the Kijima and Furukawa (2003) model.

\section{Conclusions}

This study was conducted to design a novel domain model applicable in restricted areas based on seafarers' awareness. The $\mathrm{SA}_{\text {value }}(\mathrm{s})$ of 125 seafarers sailing on the oceans were measured through the SA subjective measurement method, following which the seafarers' awareness values were quantified on the basis of three encountering situations. The awareness-based domain was constructed based on the

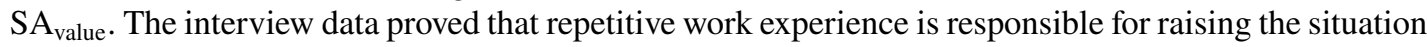
awareness claimed by the SA theory. In the navigator group, SA was improved through navigation experiences based on the ship's manoeuvrability.

The developed model is a universal and practical model reflecting different types of ships and the awareness of all ranks of seafarers'. In addition, the mechanism of the $\mathrm{DCPA}_{\mathrm{TV}}$ formation was analysed using the SA theory and sub-parameters. This shows the elements, such as $\zeta_{n}, \varepsilon_{n}$ and $\kappa_{M}$, that have most reference to the domain length. Furthermore, the parameters deemed important in the existing domain studies were different from those that the seafarers considered important. However, the research is obviously limited because it may not acquire detailed human awareness. Regardless, it is clear that seafarers operate their ships with their own distinct $\mathrm{DCPA}_{\mathrm{TV}}$ when they assess risk, safety and caution.

During the interviews, all seafarers stated that the $\mathrm{DCPA}_{\mathrm{TV}}$ varies depending on the environment of the restricted areas. In the future, based on this study, the authors will present a more practical model by applying the environmental factors of restricted areas to the existing model. Furthermore, it is necessary to obtain more interview data from seafarers with different backgrounds. 
Acknowledgements. The authors would like to express their gratitude to the 110 navigators, 14 captains and one pilot for their kind cooperation in answering the interview questions. Especially, they extend thanks to Pilot Lee and Captains Son, Yoon and Choi for the significant opinions they provided for this study.

\section{References}

Allen, C. H. (2010). Taking narrow channel collision prevention seriously to more effectively manage marine transportation system risk. Journal of Maritime Law \& Commerce, 41(1), 10-25.

Cockcroft, A. N. and Lameijer, J. N. F. (2003). Guide to the Collision Avoidance Rules. Oxford: Elsevier.

Coldwell, T. G. (1983). Marine traffic behaviour in restricted waters. The Journal of Navigation, 36, 431-444

COLREGS. (1972). Convention on the International Regulations for Preventing Collisions at Sea 1972 (with Amendments to 2007 in force from 1 December 2009). International Maritime Organization.

Davis, P. V., Dove, M. J. and Stockel, C. T. (1980). A computer simulation of marine traffic using domains and arenas. The Journal of Navigation, 33, 215-222.

Endsley, M. R. (1988). Design and Evaluation for Situation Awareness Enhancement. Proceedings of the Human Factors and Ergonomics Society Annual Meeting, Los Angeles, CA.

Endsley, M. R. (1995). Measurement of situation awareness in dynamic systems. Human factors. The Journal of the Human Factors and Ergonomics Society, 37(1), 65-84.

Endsley, M. R. and Bolstad, C. A. (1994). Individual differences in pilot situation awareness. The International Journal of Aviation Psychology, 4(3), 241-264.

Endsley, M. R. and Garland, D. J. (2000). Situation Awareness Analysis and Measurement. New York: CRC Press.

Fujii, Y. and Tanaka, K. (1971). Traffic capacity. The Journal of Navigation, 24, 543-552.

Goodwin, E. M. (1975). A statistical study of ship domains. The Journal of Navigation, 28, 329-341.

Gucma, L. and Marcjan, K. (2012). Examination of ships passing distances distribution in the coastal waters in order to build a ship probabilistic domain. Zeszyty Naukowe/Akademia Morska w Szczecinie, 32(104), 34-40.

Ha, J. H. and Gourlay, T. P. (2017). Bow and Stern Sinkage Coefficients for Cargo Ships in Shallow Open Water. PIANC Yearbook 2017.

Hansen, M. G., Jensen, T. K., Lehn-Schiøler, T., Melchild, K., Rasmussen, F. M. and Ennemark, F. (2013). Empirical ship domain based on AIS data. The Journal of Navigation, 66(6), 931-940.

Hasegawa, K. and Kouzuki, A. (1987). Automatic collision avoidance system for ships using fuzzy control (in Japanese). Journal of the Kansai Society of Naval Architects, Japan, 205, 1-10.

Hörteborn, A., Ringsberg, J. W., Svanberg, M. and Holm, H. (2019). A revisit of the definition of the ship domain based on AIS analysis. The Journal of Navigation, 72(3), 777-794.

IBM. (2020). Mayflower Autonomous Ship Project. Available at: https://newsroom.ibm.com/2020-03-05-Sea-Trials-Begin-forMayflower-Autonomous-Ships-AI-Captain [Accessed 10 Jul. 2020].

Im, N. and Luong, T. N. (2019). Potential risk ship domain as a danger criterion for real-time ship collision risk evaluation. Ocean Engineering, 194, 106610.

Inoue, K. (2000). Evaluation method of ship-handling difficulty for navigation in restricted and congested waterways. The Journal of Navigation, 53(1), 167-180.

Iwasaki, H. and Hara, K. (1986). A fuzzy reasoning model to decide the collision avoidance action (in Japanese). The Journal of Japan Institute of Navigation, 75, 69-77.

Kijima, K. and Furukawa, Y. (2003). Automatic Collision Avoidance System Using the Concept of Blocking Area. Proceeding of IFAC Conference on Maneuvering and Control of Marine Craft, Girona, Spain.

Liu, Y. and Bucknall, R. (2015). Path planning algorithm for unmanned surface vehicle formations in a practical maritime environment. Ocean Engineering, 97, 126-144.

Liu, J., Zhou, F., Li, Z., Wang, M. and Liu, R. W. (2016). Dynamic ship domain models for capacity analysis of restricted water channels. The Journal of Navigation, $\mathbf{6 9}(3), 481-503$.

MUNIN. (2016). Maritime Unmanned Navigation through Intelligence in Networks. Available at: http://www.unmanned-ship. org/munin [Accessed 10 Jul. 2020].

Park, J. and Kim, J. (2016). Predictive evaluation of ship collision risk using the concept of probability flow. IEEE Journal of Oceanic Engineering, 42(4), 836-845.

Pietrzykowski, Z. (2008). Ship's fuzzy domain-A criterion for navigational safety in narrow fairways. The Journal of Navigation, 61(3), 499-514.

Pietrzykowski, Z. and Uriasz, J. (2009). The ship domain-A criterion of navigational safety assessment in an open sea area. The Journal of Navigation, $\mathbf{6 2}(1), 93$.

Rawson, A., Rogers, E., Foster, D. and Phillips, D. (2014). Practical application of domain analysis: Port of London case study. Journal of Navigation, 67(2), 193-209.

Robards, M., Silber, G., Adams, J., Arroyo, J., Lorenzini, D., Schwehr, K. and Amos, J. (2016). Conservation science and policy applications of the marine vessel Automatic Identification System (AIS)-a review. Bulletin of Marine Science, 92, 75-103.

Silveira, P. A. M., Teixeira, A. P. and Soares, C. G. (2013). Use of AIS data to characterise marine traffic patterns and ship collision risk off the coast of Portugal. The Journal of Navigation, 66(6), 879. 
Szlapczynski, R. and Szlapczynska, J. (2016). An analysis of domain-based ship collision risk parameters. Ocean Engineering, 126, 47-56.

Szlapczynski, R. and Szlapczynska, J. (2017). Review of ship safety domains: models and applications. Ocean Engineering, 145, 277-289.

Szlapczynski, R., Krata, P. and Szlapczynska, J. (2018). Ship domain applied to determining distances for collision avoidance maneuvers in give-way situations. Ocean Engineering, 165, 43-54.

Van Iperen, W. (2015). Classifying ship encounters to monitor traffic safety on the North Sea from AIS data. TransNav: International Journal on Marine Navigation and Safety of Sea Transportation, 9, 53-60.

Wang, N. (2010). An intelligent spatial collision risk based on the quaternion ship domain. The Journal of Navigation, 63(4), 733-749.

Wang, N. (2013). A novel analytical framework for dynamic quaternion ship domains. The Journal of Navigation, 66(2), $265-281$.

Wang, Y. and Chin, H. C. (2016). An empirically calibrated ship domain as a safety criterion for navigation in confined waters. The Journal of Navigation, 69(2), 257-276.

Wang, N., Meng, X., Xu, Q. and Wang, Z. (2009). A unified analytical framework for ship domains. The Journal of Navigation, 62(4), 643 .

Wang, F. Y., Zhang, J. J., Zheng, X., Wang, X., Yuan, Y., Dai, X. and Yang, L. (2016). Where does AlphaGo go?: From Church-Turing thesis to AlphaGo thesis and beyond. IEEE/CAA Journal of Automatica Sinica, 3(2), 113-120.

Wielgosz, M. (2017). Ship domain in open sea areas and restricted waters: An analysis of influence of the available maneuvering area. TransNav: International Journal on Marine Navigation and Safety of Sea Transportation, 11(1), 99-104.

Yim, J. B., Kim, D. S. and Park, D. J. (2018). Modeling perceived collision risk in vessel encounter situations. Ocean Engineering, 166, 64-75.

Zhao, J., Wu, Z. and Wang, F. (1993). Comments on ship domains. The Journal of Navigation, 46, $422-436$. 